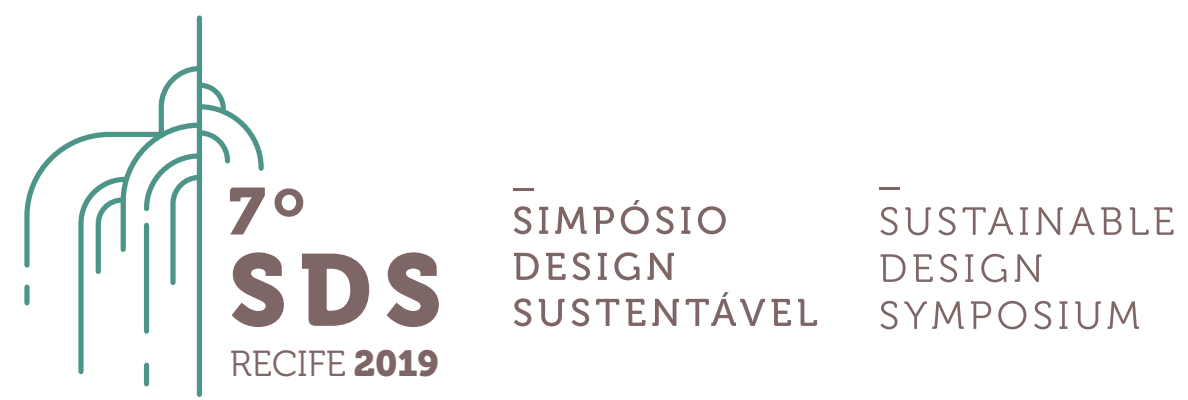

\title{
Inovação Social: investigações sobre modelo de identificação, análise e relação com os objetivos do desenvolvimento sustentável da ONU
}

\author{
Geovana Blayer Ribeiro de Assis ${ }^{1}$, Viviane G. A. Nunes ${ }^{2}$ \\ ${ }^{1}$ Universidade Federal de Uberlândia, PPGAU/FAUED, geovanablayer@gmail.com \\ ${ }^{2}$ Universidade Federal de Uberlândia, PPGAU/FAUED, viviane.nunes@ufu.br
}

\begin{abstract}
Resumo. Considerada um relevante campo de pesquisa em desenvolvimento, a Inovação Social (IS) representa hoje um potencial instrumento de contribuição em cenários contemporâneos, principalmente no que se refere à minimização de problemas sociais, os quais, em sua maioria, o Estado tem sido incapaz de solucionar. No entanto, embora a Inovação Social contribua para mitigar tais problemas, os estudos sobre o tema ainda constituem um corpo restrito de pesquisas acadêmicas, não havendo uma teoria de apoio e aplicação. Este artigo busca discutir a necessidade de uma melhor compreensão sobre a Inovação Social, especialmente no que se refere ao seu efetivo impacto (positivo) em contextos de exclusão social, bem como nas suas possíveis contribuições para o Desenvolvimento Sustentável, alinhados aos 17 Objetivos da ONU. O estudo parte de uma demanda por maiores produções bibliográficas sobre o tema, de modo a contribuir com futuras pesquisas na área. A metodologia baseia-se na revisão de literatura, a qual inclui uma investigação mais aprofundada sobre ferramentas de identificação e análise de casos de inovação social para subsidiar, posteriormente, um modelo de referência para a proposição de novos casos. Dentre os resultados, o artigo aponta para a importância da disseminação de iniciativas de Inovação Social, de modo a estabelecer a construção de cenários mais coletivos, sustentáveis e econômicos. Ainda, o artigo tem como resultado uma análise comparativa do modelo de (IS) já existente com os 17 Objetivos do Desenvolvimento Sustentável (ODS).
\end{abstract}

Palavras-chave. Design para a Inovação Social; Design e Sustentabilidade; Desenvolvimento Sustentável; 17 ODS; Modelo de identificação de casos de IS.

\section{Introdução}


O atual cenário dos contextos emergentes ${ }^{\mathrm{a}}$, marcado por um avançado desordenado das cidades e por inúmeros problemas como desigualdade social, educação, insegurança, saúde, dentre outros, confirma a necessidade da busca por novas soluções. Estas soluções, visam melhorias a grupos de socialmente excluídos, onde o Estado é ineficiente para atender as demandas prioritárias da sociedade, garantindo a elas uma melhor qualidade de vida e bem-estar. Embora seja um desafio, é essencial fomentar iniciativas que impulsionem um comportamento mais dinâmico e consciente na sociedade, contribuindo para a construção de cenários urbanos mais sustentáveis, coletivos e econômicos. Estas iniciativas, porém, dependem de um conjunto colaborativo, cujo objetivo principal seja fundamentado nas relações contínuas entre comunidades, empresas sociais e, em determinados casos, também dos órgãos públicos.

A Inovação Social tem se configurado como uma alternativa viável para o enfrentamento de problemas sociais, antes vistos como intratáveis, por meio da proposição de soluções a curto, médio e longo prazo, essencialmente com a participação dos grupos beneficiados. De forma estratégica, esta lógica de inovação tem como missão a criação de um Valor Social ou Impacto Social. Segundo Massad et al. (2017), estes termos referem-se a modelos que ultrapassam as questões mercadológicas do lucro, mas visam atender - em conjunto - interesses individuais e coletivos. Além de contribuir com melhorias à sociedade, a Inovação Social estabelece ainda conexões sociais entre grupos de indivíduos, denominados por Manzini (2008) de Comunidades Criativas. Formadas geralmente em contextos de baixa renda, tipicamente em favelas, as Comunidades Criativas possuem como tipologia de Inovação Social "Bottom Up", ou seja, de baixo para cima (MEDEIROS, 2018, P.20) e se destacam pelo uso de técnicas criativas para solucionar problemas identificados em seu cotidiano.

Nessa lógica, o Design se torna um grande aliado visto que pode se configurar como um instrumento capaz de promover soluções viáveis aos contextos locais. Ao utilizar de recursos locais existentes para a construção de melhorias urbanas, o Design para Inovação Social rompe com modelos econômicos tradicionais, propondo outros intrinsecamente mais sustentáveis, ou seja, mudanças radicais na escala local, onde uma nova postura é assumida pela sociedade. A partir de um processo de aprendizagem social difuso, são geradas as chamadas "descontinuidades sistêmicas" que, segundo Manzini (2008, p.19), refere-se a um sistema onde a sociedade é capaz de se desenvolver sem a demanda por um exacerbado consumo e produção de materiais. Além de contribuir com as dimensões social, ambiental e econômica da sustentabilidade, a Inovação Social pode colaborar com as políticas públicas orientadas ao Desenvolvimento Sustentável, também relacionados aos 17 objetivos da ONU. De acordo com o proposto documento "Transformando Nosso Mundo: a Agenda 2030 para o Desenvolvimento Sustentável", estes objetivos devem sem cumpridos até o ano de 2030 pelos países em desenvolvimento afim de garantir impactos positivos em áreas como, por exemplo, educação, saneamento, meio ambiente, dentre outros.

O presente artigo tem como objetivo investigar aspectos da Inovação Social, tais como modelos para identificação e análise de casos e sua relação com os 17 objetivos do desenvolvimento sustentável da ONU. Este trabalho integra uma pesquisa de mestrado em andamento, que pretende desenvolver um modelo de avaliação de casos de Inovação Social para identificar a efetiva contribuição das ISs quanto aos impactos nas dimensões econômica, social e ambiental da Sustentabilidade. Considerando a amplitude dos objetivos da ONU, deverá ser feita uma seleção dos objetivos a serem integrados ao modelo, com base no volume de menções identificadas durante os estudos de casos.

\footnotetext{
a Adota-se a terminologia "contextos emergentes ou de baixa renda" (VEZZOLI et al., 2018). em substituição a "em desenvolvimento"; "industrializado" em substituição a "desenvolvido"; "contextos" em substituição a "países" pois mesmo os "países desenvolvidos" podem apresentar contextos socioeconômicos diferentes.
} 


\section{Metodologia}

Este artigo adotou como metodologia uma revisão de literatura, que segundo Gerhardt e Silveira $(2009$, p.66) visa expor ideias fundamentadas nas principais abordagens já discutidas sobre o tema, porém, de forma resumida. Assim, o estudo buscou: 1) Aprofundar nas discussões teóricas sobre as dimensões econômica, social e ambiental do Desenvolvimento Sustentável, incluindo os 17 Objetivos da ONU; 2) Estudar os principais conceitos que envolvem a Inovação Social (IS), bem como sua efetiva contribuição em cenários contemporâneos, baseando-se especialmente nos autores: Afonso et al (2015), Caroli et al (2015), Chaves (2018), Eichenberg (2013), Figueiredo et al (2009), Juliani et al (2014), Manzini (2008, 2017), Massad et al (2017), e Medeiros (2018); 3) Investigar o modelo de identificação e possível análise de casos de inovação social proposto por Caroli et al (2015) no livro "Modelli ed esperienze di innovazione sociale in italia" (Modelos e experiências de Inovação Social na Italia, tradução livre), a partir de uma coletânea de 56 casos de maior relevância; e 4) Propor uma análise comparativa das dimensões identificadas no modelo existente e sua relação com os 17 Objetivos da ONU.

\section{Desenvolvimento Sustentável: Objetivos da ONU e Inovação Social}

\subsection{Os 17 Objetivos da ONU: Dimensões Econômica, Social e Ambiental da Sustentabilidade}

Nas últimas décadas, o crescimento desordenado das cidades, gerado pelo processo de industrialização, trouxe consigo a formação de um cenário urbano marcado por altos impactos ambientais. Tal fator decorrente levou a um avanço nos estudos e discussões entorno de quais eram os limites do planeta, ou seja, até onde as atividades humanas poderiam avançar de forma a não prejudicar o bem-estar e a qualidade de vida dos indivíduos, incluindo as futuras gerações (MANZINI, 2008, p.20). O alto indicativo destes impactos e a necessidade de novas soluções, fez com que novos temas começassem a ser introduzidos em políticas internacionais. Entre estes, destaca-se o surgimento da expressão Desenvolvimento Sustentável, cujo resultado é decorrente de um debate entre líderes da Comissão Mundial para o Ambiente e o Desenvolvimento (CMMAD). O debate gerou o documento Nosso Futuro Comum (Our Common Future), de 1987 (MANZINI, 2008, p.21), gerenciado por Gro Brundland, e que definiu o termo Desenvolvimento Sustentável como: "O desenvolvimento que procura satisfazer as necessidades da geração atual sem comprometer a capacidade das gerações futuras de satisfazerem as suas próprias necessidades" (PLATAFORMA AGENDA 2030)

A partir desse momento, um novo "olhar" passou a ser inserido nos debates internacionais, destacando questões como a forma em que os países deveriam repensar suas ações dentro da lógica de desenvolvimento. Estas ações, consideradas a partir de fatores econômicos, sociais e ambientais e que constituem hoje o denominado Tripé da Sustentabilidade, contribuem no processo de metas e tomadas de decisões a serem cumpridas.

Neste sistema, as questões ligadas a Dimensão Econômica deveriam representar conceitos como, por exemplo, compartilhamento, consumo solidário, comércio justo, dentre outros. Já a Dimensão Social deveria englobar aspectos como a distribuição igualitária de recursos partindo do princípio de que todos possuem direito e acesso aos recursos naturais e globais. Por fim, a Dimensão Ambiental deveria representar ações relacionadas à resiliência da biosfera-geosfera, de modo a não exceder seus limites, ou seja, preservar os recursos naturais ainda existentes (VEZZOLI et al., 2018, p.26). Diante disso, Vezzoli et al. (2018, p.15) afirma que o Desenvolvimento Sustentável deve se direcionar para as seguintes questões:

Dentro dos limites da resiliência ambiental, isto é, dentro de sua capacidade de absorção dos efeitos do impacto dos sistemas de produção e consumo sem que os mesmos repercutam em deterioração irreversível; Sem comprometer a habilidade de gerações futuras de atender suas próprias necessidades, isto é, garantir os meios ou capital natural 
que será repassado para as futuras gerações; Dentro do princípio de distribuição equânime de recursos onde todos têm o mesmo direito ao espaço ambiental, isto é, o mesmo acesso aos recursos naturais globais. (VEZZOLI et al., 2018, p.15)

Para além destes conceitos, destaca-se que, em um período histórico, os debates sobre as questões ambientais se acentuaram a partir dos anos 1980. Neste período, diversas convenções discutiam novas formas de desenvolvimento dos países, reforçando a importância de aplicação das diretrizes que norteavam o conceito de Desenvolvimento Sustentável bem como os aspectos vinculados à Sustentabilidade. Em vista disso, a cada encontro entre líderes eram estabelecidos documentos e metas a serem cumpridos pelos países a longo prazo (VEZZOLI et al, 2018, p.21).

Como exemplo, destaca-se a Conferência da Rio 92, ocorrida em 1992 no Rio de Janeiro/Brasil que elaborou a Agenda 21 (BARBOSA, 2008, p.2) definindo um plano de desenvolvimento dos países, e que destacava vários aspectos, como por exemplo, a proteção ambiental (PIMENTA \& NARDELLI, 2015, p.1259). A Rio 92 também reforçou a integração consistente do conceito de Desenvolvimento Sustentável nas políticas públicas, propondo como um modelo de orientação o desenvolvimento produtivo e social (VEZZOLI et al, p.22 e 23). Após a Conferência, um acordo rigoroso para reduzir as emissões de gases do efeito estufa foi delimitado, sente este o Protocolo de Kyoto. Vale citar ainda os Objetivos do Desenvolvimento do Milênio, incluídos em 1999 no "Pacto Global" lançado pelo Fórum Econômico de Davos, com o objetivo de "mobilizar lideranças e alinhar políticas e estratégias de desenvolvimento em áreas como meio ambiente, trabalho, direitos humanos e anti-corrupção." (VEZZOLI et al, p.23).

Em 2012, 20 anos após a realização da Rio 92, ocorre a Rio+20, que elabora o documento chamado de "O futuro que queremos", destacando questões como economia verde, erradicação da pobreza, dentre outras questões. Em 2015, a Assembleia Geral da ONU, realizada em Nova York, resultou no documento intitulado como "Transformando Nosso Mundo: a Agenda 2030 para o Desenvolvimento Sustentável". Este documento foi constituído por meio de uma estrutura com 17 objetivos e suas 169 metas a serem cumpridas, tendo elas passado por um acompanhamento e revisão. Os 17 objetivos estabelecidos, bem como suas metas, englobam ações dentro das três dimensões principais do desenvolvimento sustentável, ou seja, a econômica, a social e a ambiental. Segundo a Plataforma Agenda 2030, os 17 Objetivos da ONU estão orientados às demandas mundiais, para problemas globais que carecem de solução, conforme pode ser observado na figura 1.

Figura 1 - 17 Objetivos do Desenvolvimento Sustentável (ODS)
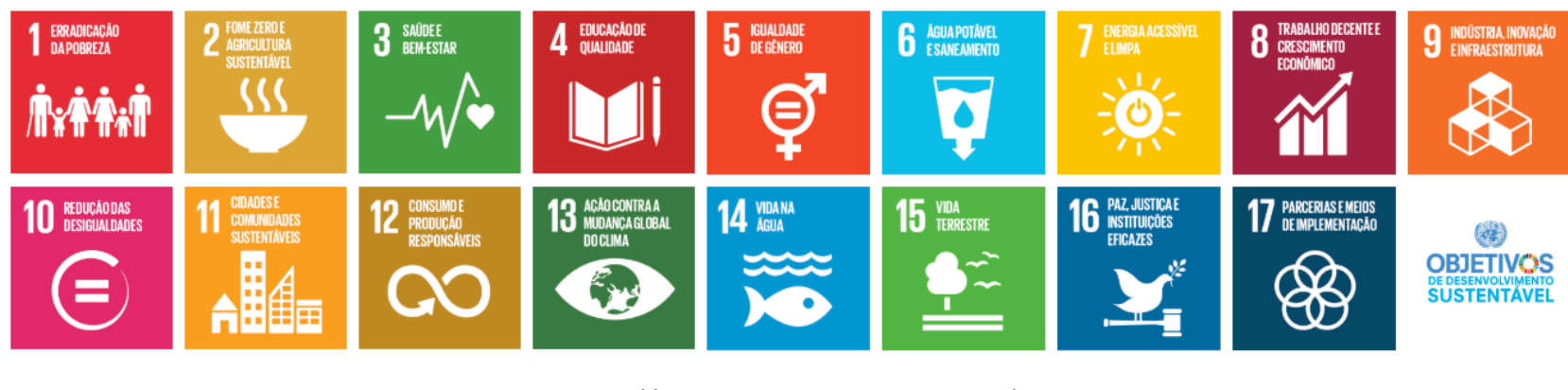

Fonte: http://www.agenda2030.com.br/ (2019)

\subsection{Inovação Social: o papel das comunidades criativas}

Além de contribuir com a Sustentabilidade e com as abordagens do Desenvolvimento Sustentável por meio da inserção de modelos de vida mais sustentáveis e econômicos, a Inovação Social desencadeia também uma série de relações sociais entre grupos de indivíduos da sociedade. Denominados por Manzini (2008) de Comunidades Criativas, esses grupos se referem a um 
sistema onde ocorre uma troca contínua de ideias, experiências e percepções sobre determinada realidade, tendo em vista a resolução de problemas do cotidiano. Segundo Eichenberg (2013, p.22) estas comunidades "estabelecem-se por meio do entendimento mútuo daqueles que participam desse contexto de forma coletiva, coproduzindo alternativas inovadoras com recursos locais de modo sustentável".

De maneira geral, estas organizações criativas provocam as chamadas Descontinuidades Sistêmicas. Este termo, também definido por Manzini (2008), refere-se a mudanças radicais na escala local, onde alterações no sistema são capazes de garantir melhorias aos contextos, contribuindo com uma redução na produção e consumo exacerbado de materiais. Estas mudanças interferem também "no modo como os indivíduos ou comunidades agem para resolver seus problemas ou criar novas oportunidades" (LAUNDRY, 2006; EMUDE, 2006 apud MANZINI 2008, p.62).

A partir da colaboração entre grupos e da inserção de métodos criativos, as Comunidades Criativas adquirem então uma tipologia de inovação "bottom up", de cima para baixo. Segundo Medeiros (2018, p.20), esta tipologia surge na base da sociedade, particularmente em favelas e contextos de baixa renda, as quais tem como "ponto de partida para seu percurso atividades de indivíduos e/ou grupos autônomos para a definição de um projeto que passa a funcionar de forma ampliada em sua comunidade".

Além das tipologias "bottom up", as Inovações Sociais podem estar relacionadas a processos do tipo: 1) top-down, "de cima para baixo", destaca iniciativas que surgem por meio de organizações maiores e governamentais; e 2) peer-to-peer, "entre pares", na qual as propostas funcionam a partir da relação entre diferentes atores que dão apoio a ideia (MEDEIROS, 2018, p.20). Um dos exemplos de interações top-down pode ser visto pela inserção do tema Inovação Social em centros de políticas governamentais como ocorre, por exemplo, com o Bureau of European Policy Advisers (BEPA) da Comunidade Europeia (2013). Em seu segundo relatório chamado "Social Innovation: a decade of changes", o governo destaca a "importância das inovações sociais nas políticas públicas, onde a co-participação do cidadão na governança é um aliado para a resposta mais direta dos governos" (CHAVES, 2018, p.122).

Por outro lado, mesmo sendo um tema de grande importância mundial, tanto em contextos industrializados quanto emergentes, a Inovação Social ainda não representa um conjunto consolidado de pesquisas, não havendo assim uma definição específica de apoio (AFONSO et al, 2015, p. 6). Tal fator pode ser justificado devido à sua ampla possibilidade de aplicação em várias áreas de atuação tais como, "educação, saúde, lazer, trabalho, saneamento básico, melhorias das condições de vida e de convivência, entre outros" (ZORZAL et al, 2016, p.2). Bignetti (2011) afirma também que:

(...) ainda que a inovação social seja uma alternativa para os problemas sociais e para a crescente preocupação com as falhas do mercado que geram desigualdades, os estudos sobre o tema "não representam parcela significativa das pesquisas acadêmicas, e o conjunto de abordagens, metodologias e práticas ainda não se constitui num corpo consolidado de conhecimentos (BIGNETTI, 2011, p.4 apud JULIANI et al. 2014, p.2)

De acordo com o relatório "Modelos e experiências de Inovação Social na Itália" a prática da Inovação Social requer o estudo e aplicação de ferramentas com base em teorias, pesquisas e práticas no campo (CAROLI et al. 2015). Isso demanda estudos mais ampliados sobre o tema, visto sua importância de aplicação em contextos de exclusão social, buscando soluções que garantem acesso à minorias sociais, onde, muitas das vezes, os recursos são escassos e o governo é incapaz de atendê-los com suas soluções. Nesse contexto, o Design pode ser aplicado como um facilitador nas iniciativas de Inovação Social, visto que pode se configurar como um instrumento que - ao 
utilizar recursos locais e criatividade, é capaz de garantir um maior acesso à populações de baixa renda. Assim como afirma Figueiredo et al (2009) :

\begin{abstract}
O design pode ser utilizado como forma de promoção de casos de inovação social. A partir de um posicionamento estratégico, podem ser realizadas ações que poderão impulsionar o desenvolvimento local. Essas iniciativas são contextualizadas, ou seja, há um cuidado especial para que as características e tradições locais sejam mantidas. Nesse tipo de estratégia, além de haver a relação entre os fatores sociais, econômicos e ambientais, tripé da sustentabilidade (SACHS, 2002), existe uma integração entre as partes interessadas (stakeholders) no processo (FIGUEIREDO et al. 2009, p.1).
\end{abstract}

A partir de uma ação estratégica e da relação entre múltiplos atores de um sistema, a Inovação Social propõe novas perspectivas para se enfrentar os problemas cotidianos de certa realidade (Manzini, 2017, p.26 e 27). Nesta lógica sistemática, além de contribuir com as iniciativas das dimensões econômica, social e ambiental da Sustentabilidade, a Inovação Social pode ser considerada também como um dos possíveis caminhos em direção ao Desenvolvimento Sustentável dos países, cujo resultado impacta diretamente nos 17 Objetivos da ONU, estes que devem ser alcançados até o ano de 2030 por países em desenvolvimento.

\title{
4 Modelos e experiências de Inovação Social (IS) na Itália: uma análise preliminar
}

O segundo relatório de Inovação Social da Itália - "Modelli ed esperienze di innovazione sociale in Italia" (CAROLI. et al. 2015) apresenta como abordagem teórica um panorama geral sobre a trajetória da Inovação Social no país. Publicado pelo CERIIS (Centro de Pesquisa Internacional sobre Inovação Social), o relatório analisa o fenômeno a partir do levantamento de 500 projetos e a investigação de 56 casos de IS com maior destaque. Tais casos são analisados conforme o Modelo e experiências de inovação social na Itália proposto no relatório (CAROLI et al. 2015, p.255 a 275). Sua característica principal está relacionada a diversos aspectos de análise que possibilitam a identificação de um caso promissor, ou seja, os principais fatores que envolvem uma iniciativa de Inovação Social (IS).

De modo geral, este relatório apresenta como conteúdo uma abordagem sobre as condições viáveis para o desenvolvimento da Inovação Social na Itália, ressaltando neste contexto as áreas de importância social onde o fenômeno é mais frequente. O documento aborda sobre questões gerais como: (i) quais são os atores envolvidos na IS; (ii) qual impacto da iniciativa de IS; (ii) de que forma a proposta de IS é gerada; dentre outros aspectos. Este estudo apresenta, como resultado, uma análise preliminar deste relatório, na forma de um Modelo de identificação $e$ análise de casos de Inovação Social (IS). A análise visa compreender melhor o documento já existente e sua correlação com as Dimensões do Desenvolvimento Sustentável e os 17 Objetivos da ONU. Dentre os objetivos buscados, a análise preliminar inclui a investigação de ferramentas de identificação e análise de casos de Inovação Social (IS) para, posteriormente, elaborar um modelo de referência para a proposição de novos casos. Este novo modelo deverá ser desenvolvido na pesquisa de mestrado em andamento já citada.

\subsection{Modelo proposto para identificação e análise de casos de Inovação Social (IS)}

A versão preliminar do Modelo de identificação e análise de casos de Inovação Social (IS) foi elaborada a partir do segundo relatório de Inovação Social Italiano e está estruturada em cinco grandes grupos e seus subitens, seguindo a mesma estrutura do modelo italiano. Os grupos estão divididos em: 1) A iniciativa: conteúdos, atividades, atores envolvidos, área geográfica; 2) Inovação e impacto social; 3) A colaboração entre diferentes atores; 4) Métodos de financiamento e sustentabilidade econômica; 5) Condições de sucesso e escalabilidade; e 6) Criticidade e medidas de apoio (CAROLI et al. 2015, p.255 a 275).

No grupo 1 são apresentados tópicos gerais que visam coletar informações sobre os casos 
de Inovação Social, tais como: a) nome da iniciativa e ano de início; b) descrição da iniciativa: atividade; c) tipo de inovação social (ex: de processo organizacional, tomada de decisão, e/ou produto ou serviço); e d) fase em que a iniciativa se encontra (ex: processamento de ideias, prototipagem, experimentação, implementação, escala, etc.). Na sequência, o documento apresenta uma tabela geral com informações voltadas a identificar a área social de impacto em que incide a iniciativa de IS, ou seja, quais são os contextos em que a Inovação Social tende a incidir (tabela 1).

Tabela 1 - Item análise do grupo 1

\begin{tabular}{|c|c|}
\hline Cuidados com à saúde & Segurança \\
\hline $\begin{array}{l}\text { Assistência social } \\
\text { - } \quad \text { Habitação social } \\
\text { - } \quad \text { Inclusão social de pessoas desfavorecidas } \\
\text { - } \quad \text { Pessoas idosas }\end{array}$ & $\begin{array}{l}\text { Formação e inclusão profissional } \\
\text { - } \quad \text { Ensino à distância } \\
\text { - } \quad \text { Teletrabalho } \\
\text { - } \quad \text { Aprimoramento de pensionistas "jovens" }\end{array}$ \\
\hline 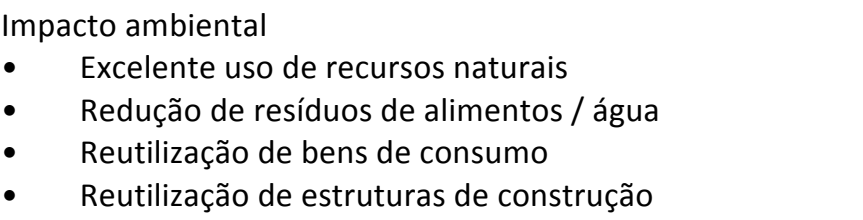 & $\begin{array}{l}\text { Compartilhando e agrupando } \\
\text { - Plataformas para compartilhamento / troca } \\
\text { de ativos. } \\
\text { - Plataformas para compartilhamento de } \\
\text { serviços. }\end{array}$ \\
\hline $\begin{array}{l}\text { Integração social } \\
\text { • } \quad \text { Integração de imigrantes } \\
\text { - } \quad \text { Integração de pessoas com deficiência }\end{array}$ & $\begin{array}{l}\text { Compartilhamento de conhecimento } \\
\text { - } \quad \text { Gerenciamento e uso de big data } \\
\text { - } \quad \text { Transferência de habilidades }\end{array}$ \\
\hline Requalificação urbana & $\begin{array}{l}\text { Serviços de interesse público } \\
\text { - } \quad \text { Mobilidade urbana }\end{array}$ \\
\hline Cultura e desenvolvimento do patrimônio cultural & Turismo Sustentável \\
\hline $\begin{array}{l}\text { Revitalização de comunidades periféricas em áreas urbanas } \\
\text { / extra-urbanas }\end{array}$ & Outro (Especifique) \\
\hline $\begin{array}{l}\text { Projetos de prestação de contas que gerenciam dados } \\
\text { abertos "open data". }\end{array}$ & \\
\hline
\end{tabular}

Fonte: Caroli et al (2015) com tradução livre pelos autores (2019)

Como pode ser observado, existe uma grande diversidade de áreas de impacto da Inovação Social que pode estar relacionada tanto às questões sociais (ex. cuidados com à saúde, integração social, segurança, serviços de interesse público, etc.) como também a questões econômicas e ambientais (ex. requalificação urbana, turismo sustentável, etc.). Ainda como parte do grupo 1, o conteúdo apresenta outras duas análises: a primeira refere-se à área territorial de incidência da iniciativa de inovação social, ou seja, qual é a escala de impacto da iniciativa (ex: bairro da grande área urbana, grande área urbana, região, nação, etc.); a segunda análise refere-se a uma identificação dos atores envolvidos na iniciativa de Inovação Social e quais os seus papéis desempenhados, como por exemplo, os financiadores da iniciativa.

O conteúdo relativo ao grupo 2 de questões aparece na tabela 2, referente à Inovação e Impacto Social, com o objetivo de avaliar o "principal motivo pelo qual a iniciativa deve ser considerada como inovadora". São indicados fatores econômicos e sociais, além de aspectos como tecnologia, produtos e/ou serviços, inovação de modelos de negócios, e outros. 
Tabela 2 - Item análise do grupo 2

\begin{tabular}{|l|l|}
\hline $\begin{array}{l}\text { PRINCIPAL MOTIVO PELO QUAL A INICIATIVA / PROJETO DEVE SER CONSIDERADA "INOVADORA" (indique a } \\
\text { resposta com um x) }\end{array}$ \\
\hline Distribuição de produtos / serviços para categorias de usuários previamente excluídos de seu uso \\
\hline Uso de novas tecnologias & $\begin{array}{l}\text { Ativação de novas relações entre os sujeitos envolvidos na implementação da atividade (colaboração } \\
\text { horizontal) }\end{array}$ \\
\hline Ativação de novas relações entre produtor e usuário (colaboração vertical) & \\
\hline Compartilhamento do valor econômico criado entre muitos atores & \\
\hline Melhoria estrutural de certas condições ambientais ou sociais, anteriormente não resolvidas \\
\hline Inovação do modelo de negócio / modelo de produção dos sujeitos envolvidos \\
\hline Outro (especifique)
\end{tabular}

Fonte: Caroli et al (2015) com tradução livre pelos autores (2019)

O grupo 3 refere-se à "Colaboração entre diferentes atores" e abrange os seguintes aspectos: a) identificar quais atores indicados no grupo 1 contribuem para que a atividade seja possível; e b) identificar o nível de inovação das colaborações fundamentais da iniciativa (ex: modalidade tradicional, pouco inovadora, muito inovadora, etc). No aspecto "a" são analisadas questões como, por exemplo, a fase em que o ator intervém na iniciativa e qual é o interesse deste em participar da IS.

O grupo 4 abrange uma análise dos "Métodos de financiamento e sustentabilidade econômica". Nesta análise são descritos: a) os métodos de financiamento da iniciativa; b) a capacidade da iniciativa para alcançar a sustentabilidade econômica financeira (ex: nada, baixo, médio, alto, total); e c) como alcançar a sustentabilidade econômica financeira indicada.

O grupo 5 trata das "Condições de sucesso e escalabilidade" e aborda os seguintes aspectos: a) os determinantes essenciais para o sucesso da iniciativa em termos de sua capacidade de resolver de modo inovador um problema social; b) a escalabilidade da iniciativa (ex: nada, discreto, bom, muito alto, etc.); c) os determinantes essenciais para a escalabilidade da iniciativa indicada; e d) o grau de compromisso com a medição dos resultados e a divulgação da inovação.

O grupo 6 de análise inclui questões referentes à "Criticidade e medidas de apoio" e aborda dois aspectos: o primeiro refere-se a uma explicação sobre como o modo como os resultados alcançados pela visão qualitativa e quantitativa são medidos; o segundo aspecto refere-se aos fatores críticos da iniciativa de Inovação Social e sua relevância (ex: nenhuma, limitada, significativa, etc). Entre os fatores críticos, o documento sugere alguns aspectos tais como: falta de atenção do público que se beneficia do IS; falta de controle sobre as condições/métodos de implementação; c) dificuldade em demonstrar a relevância do impacto; d) fraqueza organizacional e habilidades modestas das partes implementadoras, dentre outros.

\subsection{Análise comparativa do Modelo Italiano e a versão preliminar de um Modelo para Identificação e análise de casos de Inovação Social}

A análise comparativa considerou dois importantes grupos, sendo estes: 1) a iniciativa: conteúdos, atividades, atores envolvidos, área geográfica; e 2) Inovação e Impacto Social. Os itens apresentados pelas tabelas 1 e 2 foram selecionados para estudo aprofundado pois apresentam 
os aspectos mais evidentes em termos de avaliação do impacto da inovação social. Além disso, foram considerados os itens mais viáveis para se estabelecer uma correlação com os objetivos do Desenvolvimento Sustentável, visto que os demais itens consideram questões mais gerais sobre as iniciativas.

Para a construção da análise comparativa foram consideradas duas etapas principais, sendo: 1) correlação dos aspectos apresentados pelas tabelas 1 e 2 com as dimensões econômica, social e ambiental; e 2) correlação dos aspectos das tabelas 1 e 2 com os 17 objetivos da ONU. Durante as etapas, foi feita uma análise da tabela 1 e posterior da tabela 2, sendo divididas conforme as numerações de cada aspecto. Estruturada em três quadros principais divididos conforme as dimensões econômica, social e ambiental, a análise preliminar estruturou-se da seguinte forma:

Figura 2 - Análise comparativa do modelo com as dimensões do Desenvolvimento Sustentável e 17 ODS

\begin{tabular}{|c|c|c|c|c|}
\hline \multicolumn{5}{|c|}{ Dimensão Econômica } \\
\hline ITENS TABELAS & \multicolumn{4}{|c|}{17 ODS } \\
\hline 3. Impacto Ambiental & 2 & 6 & 11 & 12 \\
\hline 5. Requalificação Urbana & \multicolumn{4}{|c|}{11} \\
\hline $\begin{array}{l}\text { 7. Revitalização de comunidades } \\
\text { periféricas em áreas } \\
\text { urbanas/extra-urbanas }\end{array}$ & \multicolumn{2}{|c|}{9} & \multicolumn{2}{|c|}{11} \\
\hline $\begin{array}{l}\text { 8. Projetos de prestaçäo de contas } \\
\text { que gerenciam dados abertos } \\
\text { "open data". }\end{array}$ & \multicolumn{4}{|c|}{17} \\
\hline $\begin{array}{l}\text { 10. Formaçäo e inclusão } \\
\text { profissional }\end{array}$ & \multicolumn{4}{|c|}{4} \\
\hline 11. Compartilhando e agrupando & \multicolumn{4}{|c|}{17} \\
\hline $\begin{array}{l}\text { 12. Compartilhamento de } \\
\text { conhecimento }\end{array}$ & \multicolumn{4}{|c|}{17} \\
\hline 13. Serviços de interesse público & \multicolumn{4}{|c|}{11} \\
\hline 14. Turismo Sustentável & \multicolumn{4}{|c|}{8} \\
\hline $\begin{array}{l}\text { 1. Distribuição de produtos / } \\
\text { serviços para categorias de } \\
\text { usuários previamente excluídos de } \\
\text { seu uso }\end{array}$ & 1 & 2 & 8 & 10 \\
\hline 2. Uso de novas tecnologias & & 9 & & 17 \\
\hline $\begin{array}{l}\text { 4. Ativação de novas relações } \\
\text { entre produtor e usuário } \\
\text { (colaboraçäo vertical) }\end{array}$ & \multicolumn{4}{|c|}{17} \\
\hline $\begin{array}{l}\text { 5. Compartilhamento do valor } \\
\text { económico criado entre muitos } \\
\text { atores }\end{array}$ & \multicolumn{4}{|c|}{17} \\
\hline $\begin{array}{l}\text { 7. Inovaçäo do modelo de negócio } \\
\text { / modelo de produção dos sujeitos } \\
\text { envolvidos }\end{array}$ & \multicolumn{4}{|c|}{17} \\
\hline
\end{tabular}

\begin{tabular}{|c|c|c|c|c|}
\hline \multicolumn{5}{|l|}{ Dimensão Social } \\
\hline ITENS TABELAS & \multicolumn{4}{|c|}{17 ODS } \\
\hline 1.Cuidados com à saúde & \multicolumn{2}{|c|}{3} & \multicolumn{2}{|c|}{2} \\
\hline 2.Assistência Social & 1 & \multicolumn{2}{|c|}{10} & 11 \\
\hline 4. Integração Social & 4 & 8 & 10 & 11 \\
\hline 5. Requalificação Urbana & \multicolumn{4}{|c|}{11} \\
\hline $\begin{array}{l}\text { 6. Cultura e valorização do patrimônio } \\
\text { cultural }\end{array}$ & \multicolumn{4}{|c|}{11} \\
\hline $\begin{array}{l}\text { 7. Revitalização de comunidades periféricas } \\
\text { em áreas urbanas/extra-urbanass }\end{array}$ & \multicolumn{2}{|c|}{9} & \multicolumn{2}{|c|}{11} \\
\hline 9. Segurança & \multicolumn{2}{|c|}{5} & \multicolumn{2}{|c|}{16} \\
\hline 10. Formaçäo e inclusão profissional & \multicolumn{4}{|c|}{4} \\
\hline 11. Compartilhando e agrupando & \multicolumn{4}{|c|}{17} \\
\hline 12. Compartilhamento de conhecimento & \multicolumn{4}{|c|}{17} \\
\hline 13. Serviços de interesse público & \multicolumn{4}{|c|}{11} \\
\hline 14. Turismo Sustentável & \multicolumn{4}{|c|}{8} \\
\hline $\begin{array}{l}\text { 1. Distribuiçäo de produtos / serviços para } \\
\text { categorias de usuários previamente } \\
\text { excluídos de seu uso }\end{array}$ & 1 & 2 & 8 & 10 \\
\hline $\begin{array}{l}\text { 3. Ativaçäo de novas relações entre os } \\
\text { sujeitos enwolvidos na implementaçäo da } \\
\text { atividade (colaboração horizontal) }\end{array}$ & \multicolumn{4}{|c|}{17} \\
\hline $\begin{array}{l}\text { 4. Ativaçäo de novas relações entre produtor } \\
\text { e usuário (colaboração vertical) }\end{array}$ & \multicolumn{4}{|c|}{17} \\
\hline $\begin{array}{l}\text { 6. Melhoria estrutural de certas condições } \\
\text { ambientais ou sociais, anteriormente não } \\
\text { resolvidas }\end{array}$ & \multicolumn{4}{|c|}{17} \\
\hline $\begin{array}{l}\text { 7. Inovação do modelo de negócio / modelo } \\
\text { de producão dos sujeitos envolvidos }\end{array}$ & \multicolumn{4}{|c|}{17} \\
\hline
\end{tabular}
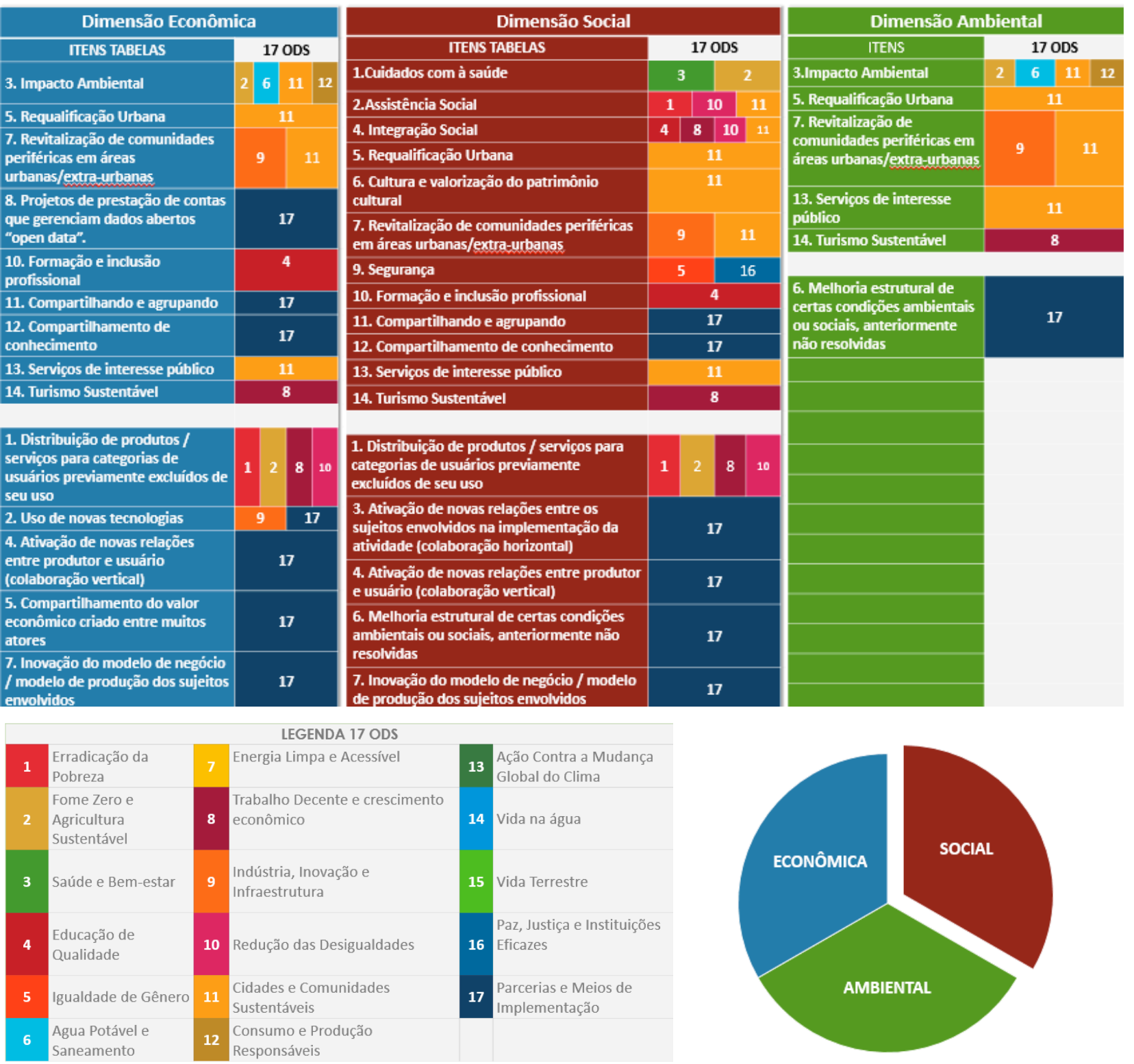

Fonte: Elaborado pelos autores (2019)

Como pode ser observado na figura 2, em cada coluna corresponde às dimensões (econômica, social e ambiental) são apontados os aspectos das tabelas 1 e 2 correspondentes às suas áreas de impacto, bem como a relação dos mesmos com os 17 ODS. De forma geral, a 
dimensão econômica correspondeu a nove itens da tabela 1 e cinco da tabela 2; já a dimensão social a 12 itens da tabela 1 e cinco itens da tabela 2; por fim, a dimensão ambiental correspondeu a cinco itens da tabela 1 e apenas um item da tabela 2. A análise preliminar considerou de forma resumida como resultado as seguintes questões:

\section{- Tabela 1: Área social de impacto em que incide a iniciativa}

1. Cuidados com à saúde - corresponde à dimensão social e relaciona-se aos objetivos 2 e 3 da ONU que abordam questões como: a) redução da mortalidade infantil; b) fim de epidemias de doenças como AIDS, tuberculose, etc.; c) eliminação da desnutrição, etc.

2. Assistência social - corresponde à dimensão social e relaciona-se aos objetivos 1,10 e 11 da ONU, estes que abordam questões como: a) eliminação da pobreza em todas as suas formas; b) garantia de direitos iguais a todos, com acesso a recursos econômicos e serviços básicos; c) promoção da inclusão social de pessoas e distribuição de oportunidades de forma igualitária; d) garantia do acesso a habitação segura, adequada.

3. Impacto ambiental - corresponde às dimensões econômica e ambiental e relaciona-se aos objetivos 2, 6, 11 e 12 da ONU. Estes que abordam questões como, por exemplo: a) reuso de materiais locais para a construção; b) uso de sistemas sustentáveis para a produção de alimentos; c) melhorias na qualidade da água para reduzir a poluição, etc.

4. Integração social - corresponde à dimensão social e relaciona-se aos objetivos 4, 8, 10 e 11 da ONU. Estes que abordam questões como: a) igualdade de acesso a todos os níveis de educação e formação profissional para os mais vulneráveis, incluindo pessoas com deficiência; b) emprego para jovens e pessoas com deficiência, etc.

5. Requalificação urbana - corresponde às dimensões econômica, social e ambiental e relaciona-se ao objetivo 11 da ONU. Este que aborda questões como, por exemplo: a) proporcionar o acesso universal a espaços públicos seguros, inclusivos, acessíveis e verdes; b) aumentar a urbanização inclusiva, etc.

6. Cultura e valorização do patrimônio cultural - corresponde à dimensão social e relacionase ao objetivo 11 da ONU. Este que aborda questões como: a) fortalecer esforços para proteger e salvaguardar o patrimônio cultural e natural do mundo.

7. Revitalização de comunidades periféricas em áreas urbanas/extra-urbanas - corresponde às dimensões econômica, social e ambiental e relaciona-se aos objetivos 9 e 11 da ONU. Estes que abordam questões como, por exemplo: a) desenvolver infraestrutura de qualidade, confiável, sustentável e resiliente; b) proteger patrimônios públicos, etc.

8. Projetos de prestação de contas que gerenciam dados abertos "open data" - corresponde à dimensão econômica e relaciona-se ao objetivo 17 da ONU. Este que aborda questões como, por exemplo: a) reforçar a parceria global entre países; b) incentivar e promover parcerias público-privadas e com a sociedade civil eficazes, a partir da experiência das estratégias de mobilização de recursos dessas parcerias, etc.

9. Segurança - corresponde à dimensão social e relaciona-se aos objetivos 5 e 16 da ONU. Estes que abordam questões como: a) eliminar todas as formas de violência contra mulher; b) reduzir significativamente todas as formas de violência e as taxas de mortalidade relacionada em todos os lugares, etc.

10. Formação e inclusão profissional - corresponde às dimensões econômica e social e relaciona-se ao objetivo 4 da ONU. Este que aborda questões como: a) direito à educação por todos, incluindo minorias sociais; b) oportunidades de aprendizado e crescimento, etc. 
11. Compartilhando e agrupando - corresponde as dimensões econômica e social e relacionase ao objetivo $17 \mathrm{da}$ ONU.

12. Compartilhamento de conhecimento - corresponde às dimensões econômica e social e relaciona-se também ao objetivo 17 da ONU.

- Ambos aspectos 11 e 12 consideram o objetivo 17 em questões como: a) reforçar a parceria global para o desenvolvimento sustentável; b) estabelecer trocas e o compartilhamento entre países;

13. Serviços de interesse público - corresponde às dimensões econômica, social e ambiental e relaciona-se ao objetivo 11 da ONU. Este que aborda questões, como: a) acesso a transportes seguros, acessíveis e sustentáveis.

14. Turismo Sustentável - corresponde às dimensões econômica, social e ambiental e relaciona-se ao objetivo 8 da ONU, que aponta: a) até o ano de 2030, elaborar e implementar políticas para promover o turismo sustentável, que gera empregos e promove a cultura e os produtos locais.

- Tabela 2: Motivo para o qual a iniciativa/projeto deve ser considerada "inovadora".

1. Distribuição de produtos/serviços para categorias de usuários previamente excluídos de seu uso - corresponde as dimensões econômica e social e relaciona-se aos objetivos 1, 2, 8 e 10 da ONU. Estes objetivos abordam questões como, por exemplo: a) direito ao acesso de recursos econômicos e sistemas básicos; b) sustentar o crescimento econômico;

2. Uso de novas tecnologias - corresponde à dimensão econômica e relaciona-se aos objetivos 9 e 17 da ONU, estes que abordam questões como, por exemplo: a) aumentar o acesso a tecnologias de informação; b) apoiar o desenvolvimento tecnológico, etc.

3. Ativação de novas relações entre os sujeitos envolvidos na implementação da atividade (colaboração horizontal) - corresponde à dimensão social e relaciona-se ao objetivo 17.

4. Ativação de novas relações entre produtor e usuário (colaboração vertical) - corresponde às dimensões econômica e social e relaciona-se ao objetivo 17 da ONU.

5. Compartilhamento do valor econômico criado entre muitos atores - corresponde à dimensão econômica e relaciona-se ao objetivo 17 da ONU.

6. Melhoria estrutural de certas condições ambientais ou sociais, anteriormente não resolvidas - corresponde às dimensões social e ambiental e relaciona-se ao objetivo 17.

7. Inovação do modelo de negócio/modelo de produção dos sujeitos envolvidos corresponde a dimensão econômica e social e relaciona-se ao objetivo 17 da ONU.

- Destaca-se que, os aspectos 3 a 7 correspondem somente ao objetivo 17 pois envolvem questões como, por exemplo: a) fortalecer a mobilização de recursos internos, inclusive por meio do apoio internacional aos países em desenvolvimento; b) mobilizar recursos financeiros adicionais para os países em desenvolvimento a partir de múltiplas fontes, dentre outros.

\section{Discussões}

A partir da base teórica e dos conceitos estudados, no que se refere às abordagens sobre o Desenvolvimento Sustentável, 17 Objetivos da ONU e Inovação Social, foi possível estabelecer relação entre todos os aspectos identificados. Dentre eles, os principais estão relacionados às ações a serem realizadas para implementar objetivos propostos, a fim de garantir melhorias globais, reduzir os impactos ambientais, promover o bem-estar e a qualidade de vida social, bem 
como preservar recursos para as futuras gerações.

A meta proposta até o ano de 2030, torna o cumprimento dos 17 Objetivos da ONU, mais que uma necessidade, um enorme desafio coletivo. Nesse contexto, entende-se que a Inovação Social, além de ser uma estratégia de ação que contribui no alcance de, ao menos parte dos 17 objetivos, é também uma potencial ferramenta de transformação local e global, cujo resultado será visto a partir rompimento de modelos econômicos tradicionais e o estabelecimento de ações mais coletivas, sustentáveis e econômicas.

Compreender a dinâmica da inovação social e os principais fatores que envolvem sua implementação é, portanto, uma abordagem teórica que precisa ser ampliada. O conjunto de teorias e modelos que identificam e avaliam o impacto da Inovação Social ainda não representam um material consolidado de pesquisas, logo necessitam de maiores produções bibliográficas. Como parte dessa ampliação de estudos sobre a Inovação Social, bem como as abordagens teóricas sobre o Desenvolvimento Sustentável e os 17 ODS, a análise preliminar apresentada, possibilitou uma maior avaliação do Modelo e experiências Inovação Social italiano (CAROLI. et al. 2015). O modelo, além de ilustrar vários aspectos para a identificação de casos de Inovação Social, apresenta fatores que se relacionam com os objetivos do Desenvolvimento Sustentável, como visto pela figura 2 .

De modo geral, a estrutura conceitual do modelo é viável para identificação e análise de casos de Inovação Social, porém a inclusão de outros aspectos mais detalhados pode contribuir para a melhor interpretação dos casos de Inovação Social. Entre estes aspectos, vale destacar como exemplo, questões ligadas à durabilidade/permanência da iniciativa e sucesso dos casos de Inovação Social, bem como as principais condições para o seu desenvolvimento e ampliação.

A análise preliminar possibilitou, ainda que em nível inicial, observar uma recorrência maior de aspectos voltados a dimensões sociais, incluindo fatores como cuidados com a saúde, integração social, inclusão social, dentre outras questões. Nota-se também que a dimensão econômica apresenta vários aspectos recorrentes, tais como tecnologia, distribuição de serviços, serviços de interesse público, e outros. Em contrapartida, a dimensão ambiental não apresenta recorrência de aspectos no estudo, e considerada um fator de menor importância no modelo analisado.

\section{Considerações finais}

O estudo possibilitou compreender a relevância da Inovação Social como campo de pesquisa, capaz de se configurar como instrumento adequado para promover mudanças radicais na escala local (Manzini, 2008). Seu potencial está fortemente relacionado à capacidade de transformação de contextos emergentes ou de baixa renda, marcados por inúmeros problemas sociais, econômicos e ambientais. Neste cenário, ao viabilizar melhorias a estes contextos, a Inovação Social pode adquirir um papel estratégico, sendo implementada a partir de iniciativas que visem soluções a curto, médio e longo prazo. Importante que estas iniciativas busquem, além da solução de um problema identificado, principalmente garantir o bem-estar social e a qualidade de vida dos indivíduos, contribuindo também para a preservação de recursos às futuras gerações.

Ao estabelecer estas iniciativas, a Inovação Social contribui para o rompimento de modelos econômicos tradicionais, caracterizados por um consumo e produção de materiais exacerbado. Nesse processo, além de estimular a busca por soluções mais viáveis, a IS também auxilia no fortalecimento de novos modelos ao sistema, cuja ações são moldadas por conjuntos mais coletivos e sustentáveis. Aliado a este sistema integrado e complexo, de soluções coletivas e locais, o Design torna-se um grande aliado na promoção de iniciativas de Inovação Social, a partir do momento em que se utiliza da criatividade como recurso para promover soluções de baixo 
custo e alto impacto. Tais soluções podem ser aplicadas pelos próprios grupos de comunidades criativas, os quais, a partir de uma troca continua de experiências, conhecimentos e percepções sobre determinada realidade enfrentada, são capazes de garantirem soluções inovadoras e que contribuem para melhorias urbanas.

No que se refere à superação de modelos econômicos tradicionais, percebe-se que a Inovação social é um dos caminhos possíveis em direção ao Desenvolvimento Sustentável, em suas dimensões econômica, social e ambiental e uma interlocução com os 17 ODS. Dentre os aspectos positivos, a análise preliminar do modelo italiano possibilitou: (i) compreender a estrutura conceitual de identificação e análise de casos de Inovação Social; (ii) identificar a relação do modelo com as dimensões do Desenvolvimento Sustentável; e (iii) avaliar a possível contribuição dos aspectos apresentados pelo modelo dentro dos 17 ODS. ,Contudo, uma afirmação mais concreta da efetividade das iniciativas de Inovação Social e seus impactos e interrelações depende do aprofundamento dos estudos em andamento, bem como o cruzamento de dados das dimensões do Desenvolvimento Sustentável. Espera-se que o modelo em desenvolvimento possa contribuir para ampliar a compreensão das iniciativas, bem como auxiliar na manutenção das experiências existentes e, ainda, potencializar o desenvolvimento de novas iniciativas de impacto social, ambiental e econômico em comunidades locais, de maneira participativa e efetiva.

\section{Referências}

AFONSO, R; CIPOLLA, C; JOLY, M. P; BARTHOLO, R. Transit Project: Inovação e Empreendedorismo Social na América Latina. IX WORKSHOP DE LA RED EMPRENDESUR, Promoviendo el Emprendedorismo Innovador en América Latina, realizado em junho de 1015 em Mar Del Plata, Argentina. de 2015.

BARBOSA, Gisele Silva. O Desafio do Desenvolvimento Sustentável. Revista Visões 4ạ Edição, no4, $\begin{array}{llllll}\text { Volume } & 1 & - & \text { Jan/Jun, } & 2008 . & \text { Disponível }\end{array}$ <http://www.fsma.edu.br/visoes/ed04/4ed_O_Desafio_Do_Desenvolvimento_Sustentavel_Gisele .pdf>. Acesso em: 09 de novembro de 2018.

CAROLI, M. G. et al. Modelli ed Esperienze di Innovazione Sociale in Italia: Secondo Rapporto Sull'Innovazione Sociale; International Center for Research on Social Innovation (CERIIS): Milano, Italia, 2015. (In Italian).

CHAVES, Liliane Iten. Do design de produto às inovações sociais como resposta às causas diretas e indiretas dos impactos ambientais e sociais. p. 107 -128. In: Design, Artefatos e Sistema Sustentável. São Paulo: Blucher, 2018. Disponível em: <http://pdf.blucher.com.br.s3saeast1.amazonaws.com/openaccess/9788580392982/05.pdf>Acesso em: 10 de novembro de 2018.

EICHENBERG, C. H; Inovação Social: Um desafio para o design: o papel do design estratégico no processo de inovação social. Dissertação de Mestrado em Design - Universidade do Vale do Rio dos Sinos. Porto Alegre, 2013.

FIGUEIREDO, Luiz Fernando Gonçalves de; MERINO, Eugenio; MUNIZ, Marco Ogê; MERINO, Giselle. Aplicação do design em casos de Inovação Social do Estado de Santa Catarina. Santa Catarina, 2009.

GERHARDT, T. E.; SILVEIRA, D. T. (organizadores). Métodos de Pesquisa. Coordenado pela Universidade Aberta do Brasil - UAB/UFRGS e SEAD/UFRGS. Porto Alegre: Editora da UFRGS, 2009.

JULIANI, D. P; JULIANI, J. P; SOUZA, J. A. de; HARGER, E. M. Inovação Social: perspectivas e desafios. Revista Espacios, Santa Catarina, v.35 (no35), 2014. 
MASSAD, D, O, de; FOSSARI, I, M; LAPOLLI, E, M; "Inovação social e empreendedorismo social: uma revisão integrativa", p. 87 -108. In: Design e Inovação Social. São Paulo: Blucher, 2017. ISBN: 9788580392647, DOI 10.5151/9788580392647-05

MANZINI, E. Design para inovação social e sustentabilidade: Comunidades Criativas, organizações colaborativas e novas redes projetuais. Coordenação de tradução Carla Cipolla; Rio de Janeiro: E- Papers (Cadernos do grupo de Altos Estudos; v. 1, 2008.

MANZINI, E. Design: quanto todos fazem design. Uma introdução ao design para a inovação social. Coordenação de tradução Luzia Araújo. _ São Leopoldo, RS: Ed. UNISINOS, 2017.

MEDEIROS, Carolina Beltrão de. Expansão de Iniciativas de Inovação Social: Uma proposição adaptativa para análise de percursos. Tese (Doutorado em Administração) - Universidade Federal de Pernambuco. Recife, 2018.

PIMENTA, M, F, F; NARDELLI, A, M, B. Desenvolvimento Sustentável: os avanços na discussão sobre os temas ambientais lançados pela conferência das Nações Unidas sobre 0 desenvolvimento sustentável, Rio $+\mathbf{2 0}$ e os desafios para os próximos $\mathbf{2 0}$ anos. PERSPECTIVA, Florianópolis, v. 33, n.3, p.1257-1277, set. /dez.2015. Disponível em: <https://periodicos.ufsc.br/index.php/perspectiva/article/viewFile/2175795X.2015v33n3p1257/p dfa>. Acesso em: 10 de novembro de 2018.

PLATAFORMA AGENDA 2030. Acelerando as transformações para a Agenda 2030 no Brasil. Disponível em: < http://www.agenda2030.com.br/>. Acesso em 12 de novembro de 2018.

VEZZOLI, C; KOHTALA, C; SRINIVASA, A; DIEHL, J.C.; FUSAKUL, S, M; XIN, L; SATEESH, D; SANTOS, A. dos; CHAVES, L. I; CASTILLO, L. C.; GÓMEZ, C. R. P; NUNES, V. G. A.; LEPRE, P. R.; ENGLER, R. C.; MARTINS, S. B. Sistema produto + serviço sustentável: fundamentos. (Traduzido por Aguinaldo dos Santos). Curitiba, PR: Insight, 2018.

ZORZAL, I, D.; MOUCHREK, N, M; FRANCO, A, G; MAIA, M, R.; "CASOS DE INOVAÇÃO SOCIAL NA ÍNDIA: DESIGN PARA OS OUTROS 90\%", p. 3258-3273. In: Anais do 12을 Congresso Brasileiro de Pesquisa e Desenvolvimento em Design [Blucher Design Proceedings, v. 9, n. 2]. São Paulo: Blucher, 2016. 